\section{Potassium Starvation Increases Stomatal Conductance in Olive Trees}

\author{
Octavio Arquero \\ Centro de Investigación y Formación Agraria, IFAPA, Apdo. 3092, E-14080, \\ Córdoba, Spain
}

\author{
Diego Barranco and Manuel Benlloch ${ }^{1}$ \\ Departamento de Agronomía, Escuela T.S. Ingenieros Agrónomos y de Montes, \\ Universidad de Córdoba, Apdo. 3048, E-14080, Córdoba, Spain
}

Additional index words. Olea europaea, potassium status, water content, water stress, wateruse efficiency

\begin{abstract}
The effects of potassium (K) status and water availability in the growth medium on growth, water content, water-use efficiency and stomatal conductance was studied in mist-rooted 'Chemlali de Sfax' olive (Olea europaea L.) cuttings grown in a perlite substrate. Potassium starvation produced dehydration of all parts of the plant, reduced shoot growth and water-use efficiency. By contrast, $K$ starvation enhanced stomatal conductance in well-irrigated plants and, even more, in water-stressed plants. These results suggest that moderate $K$ deficiency in olives may impair the plant's ability to regulate stomatal closure; this may account for the dehydration observed in K-starved plants, particularly in situations of water stress. This result is of great importance for agricultural practices of this crop, because $K$ status, which may not be considered deficient, can cause disorders in olive trees.
\end{abstract}

The olive (Olea europaea) is grown in areas with a Mediterranean climate. Worldwide, the crop occupies a total surface area of $10 \times 10^{6}$ ha, of which only $10 \%$ is irrigated. The olivetree is able to withstand long periods of hot, dry weather, due to various morphological and physiological mechanisms, which enable it both to avoid excessive water loss through the leaves and to absorb water from soils with low water potential.

The olive leaf displays xerophytic characteristics, with a thick cuticle on both limb surfaces and underside stomata protected by peltate hairs (Bacelar et al., 2004; Rapoport, 2001). In drought conditions, the olive is able efficiently to regulate ostiole closure (Fernández et al., 1997; Giorio et al., 1999; Moriana et al., 2002). Given these features, and the plant's ability to take up water from soils with low water content, even below wilting point (Orgaz and Fereres, 2001; Xiloyannis et al., 1999), it is clear that in water-stress situations the olive displays greater water-use efficiency than other species (Fereres, 1984). Even so, in unirrigated olive plantations and in drought conditions, symptoms of dehydration are often observed, including marginal and apical necrosis of the limb, leaf drop and fruit abscission; these symptoms have been associated with low leaf potassium $(\mathrm{K})$ content (Fernández-Escobar et al., 1994; Parra et al., 2003).

It is widely assumed, though not sufficiently proved, that $\mathrm{K}$ favors cell hydration, and that deficiency of this ion causes tissue dehydration

Received for publication 27 Sept. 2005. Accepted for publication 18 Nov. 2005. This work was supported by the Ministerio de Educación y Cultura (Spain) under grants numbered AGL 2002-04560-C02 and AGL 2001-2447

'Corresponding author; e-mail ag1bemam@uco.es.
(Mengel and Kirkby, 1987). $\mathrm{K}$ is the major osmotic solute in plants (Wyn Jones et al., 1979). Its accumulation in the cell creates the water potential needed for water uptake and for generating the cell turgor required for growth (De la Guardia and Benlloch, 1980; Mengel and Arneke, 1982), as well as prompting stomatal opening (Fischer, 1968). At the wholeplant level, $\mathrm{K}$ is also involved in the osmotic uptake of water by the root (Läuchli, 1984), and in regulating root hydraulic conductivity (Quintero et al., 1998).

Despite its evident interest, relatively little research has addressed the relationship between potassium nutrition and plant water status. $\mathrm{K}$ fertilization is reported to attenuate the negative effects of water stress in faba bean (Abdel-Wahab andAbd-Alla, 1995), sugar cane (Sudama et al., 1998), rice (Tiwari et al., 1998), and sunflower (Lindhauer, 1985) plants. This positive effect of $\mathrm{K}$ fertilization, however, is not uniformly reported for all crops, and little is known about the role of potassium nutrient levels in regulating plant water status. Although K deficiency is generally associated with decreased transpiration rates, most studies attributing stomatal closure to K deficiency have tended to focus on plants at a very advanced stage of nutritional deficiency (Hsiao and Läuchli, 1986).

The main nutritional problem that exists in the areas where olive trees are traditionally cultivated is potassium deficiency (FernándezEscobar et al., 1994; Parra et al., 2003). K deficiency (K leaf concentration below $0.4 \%$ of dry weight), in unirrigated olive plantations, often causes very important symptoms of dehydratation, like leaf drop and fruit abscission (Fernández-Escobar et al., 1994; Parra et al., 2003). These symptoms are easily reproduced under controlled conditions. The objective of our work was to study the cause of that dehy- dratation. For this reason, the research was carried out in a moderate deficiency status not showing severe symptoms of K deficiency. This latent deficient status is called in the manuscript moderate K deficiency or K starvation. Severe $\mathrm{K}$-deficient plants could not be used because there is no point in analyzing the water flow in necrotic and senescent leaves. Possibly, this is the cause of the contradictory results of the effect of the potassium nutritional status on the stomatal conductance. The cultivar studied, 'Chemlali de Sfax', is usually grown in unirrigated conditions, in low-rainfall areas of southern Tunisia.

\section{Materials and Methods}

Plant material and growth conditions. Mist-rooted 'Chemlali de Sfax' olive cuttings were transferred to 1.5-L plastic pots containing perlite and placed in a greenhouse at $30 / 15^{\circ} \mathrm{C}$ (day/night) with a $14 \mathrm{~h}$ photoperiod. Before treatments, plants were watered three times a week with $150 \mathrm{~mL}$ of a $\mathrm{K}$-free standard nutrient solution supplemented with $0.01 \mathrm{mM}$ $\mathrm{KCl}$. The composition of the standard nutrient solution was as follows: $2.5 \mathrm{mMCa}\left(\mathrm{NO}_{3}\right)_{2}, 1.0$ $\mathrm{mM} \mathrm{MgSO}, 0.25 \mathrm{mM} \mathrm{Ca}\left(\mathrm{H}_{2} \mathrm{PO}_{4}\right)_{2}, 12.5 \mu \mathrm{M}$ $\mathrm{H}_{3} \mathrm{BO}_{3}, 1.0 \mu \mathrm{M} \mathrm{MnSO}_{4}, 1.0 \mu \mathrm{M} \mathrm{ZnSO}_{4}, 0.25$ $\mu \mathrm{M} \mathrm{CuSO}_{4}, 0.2 \mu \mathrm{M}\left(\mathrm{NH}_{4}\right)_{6} \mathrm{Mo}_{7} \mathrm{O}_{24}$, and $10 \mu \mathrm{M}$ Fe-ethylenediamine-di- $O$-hydroxy-phenylacetic acid. In all cases, $\mathrm{Ca}(\mathrm{OH})_{2}$ was used to adjust the $\mathrm{pH}$ of the nutrient solution to 5.5. After 100 d of acclimation, shoots were pruned to a single shoot per plant and four treatments were established.

Treatments and experimental design. Two factors were studied simultaneously, each at two levels: availability of water and of $\mathrm{K}$ in the culture medium, giving a total of four treatments. Other environmental factors-light, temperature and atmospheric humidity — were maintained at optimum levels throughout growth. The two water regimes were irrigation to field capacity (irrigated) and irrigation deficit (drought); for each regime, two $\mathrm{KCl}$ concentrations were used in the nutrient solution: 2.5 (normal K) and $0.05 \mathrm{~mm}$ (low K).

Water-availability levels were determined as follows: at the start of treatment, all plant pots were watered to field capacity, sealed above and below with impermeable material to prevent water loss by evaporation, and weighed. Thereafter, pots were weighed individually on a weekly basis, and each pot was provided with the volume of nutrient solution required by the treatment under study: for the two irrigated treatments, pots were watered until initial weights were reached; for the two drought treatments, pots were watered only when levels fell below $50 \%$ of field capacity, and only sufficiently to return water content to the $50 \%$ level. The volume of water retained by the perlite at field capacity had previously been established by weight difference.

A random-block factorial experimental design was used, with 10 replications for treatment. Analysis of variance and means separation were performed using the Statistix version 1.0 software package.

Data collection. Plants were allowed to 
grow for $93 \mathrm{~d}$ from the start of treatments, after which growth data were collected: shoot length, leaf area, and root dry weight. Above-ground growth data were taken from the post-treatment growth area of the shoot. Root data refer to total growth.

Leaf area was calculated by measuring all the leaves on the shoot using an area meter (AM200; ADC BioScientific Limited) and root dry weight was measured after oven drying at $80{ }^{\circ} \mathrm{C}$ for $3 \mathrm{~d}$.

Water-use efficiency was determined at the end of the experiment, as a function of newshoot dry weight and water consumed since the start of treatment.

Stomatal conductance was measured throughout the day in three plants per treatment and three leaves per plant, using a porometer (LI-1600; LI-COR, Lincoln, Neb.). Measurements were made on 22 Aug., at 1-h intervals from 2:00 AM to 8:00 PM, in fully developed leaves in the central area of the shoot.

Potassium was determined by atomic absorption spectrophotometry (Analyst 300; Perkin Elmer) after extraction from roots, shoots or leaves by ashing at $550{ }^{\circ} \mathrm{C}$; ashes were dissolved with $1 \mathrm{~N} \mathrm{HCl}$. Before ashing, roots were individually washed for $5 \mathrm{~min}$ in $150 \mathrm{~mL}$ of a cold $5 \mathrm{mM} \mathrm{CaSO}_{4}$ solution $\left(5^{\circ} \mathrm{C}\right)$ to allow exchange of cell wall contents.

\section{Results and Discussion}

After $93 \mathrm{~d}$ of growth, the four treatment groups differed in terms of $\mathrm{K}$ content in leaf, shoot and root, interaction between water availability and $K$ availability in the growth medium was significant for all plant organs studied. Although no symptoms of K deficiency were apparent in leaves from any of the treatment. Leaf $\mathrm{K}$ content was in all cases greater than $0.4 \%$ of dry weight (Table 1 ).

In the three plant parts studied (leaf, shoot, and root), the highest K levels were recorded in plants watered to field capacity with a nutrient solution containing $2.5 \mathrm{mM} \mathrm{KCl}$ (irrigated-normal K). The lowest $\mathrm{K}$ concentrations were found in plants watered to field capacity with the solution containing a smaller amount of $\mathrm{K}$ (irrigated-low K). Differences between these two treatments were more marked in shoots and roots than in leaves (Table 1). In all plant organs studied, variations in water availability had less effect on $\mathrm{K}$ content when the K concentration in the nutrient solution was low $(0.05 \mathrm{mM})$. The effect of $\mathrm{K}$ in the growth medium on $\mathrm{K}$ accumulation in plant organs was less marked in drought plants (Table. 1).

Availability of water and of K in the growth medium also affected plant growth, although there was a difference in effect between the aerial portion of the plant and the roots. In

Table 1. Effect of water availability in the growth medium (irrigation vs. drought) and K concentration in irrigation water (normal K vs. low K) on K concentration (percent dry weight) in leaves, shoots, and roots. For all treatments, values are means of 10 replications \pm standard error. Interaction between water availability and $\mathrm{K}$ concentration was significant for all plants organs studied.

\begin{tabular}{lccc}
\hline Treatment & Leaf & Shoot & Root \\
\hline Irrigated-normal K & $1.8 \pm 0.04$ & $2.1 \pm 0.09$ & $0.7 \pm 0.034$ \\
Irrigated-low K & $0.5 \pm 0.03$ & $0.2 \pm 0.02$ & $0.1 \pm 0.004$ \\
Drought-normal K & $0.8 \pm 0.05$ & $0.8 \pm 0.05$ & $0.2 \pm 0.006$ \\
Drought-low K & $0.6 \pm 0.02$ & $0.4 \pm 0.03$ & $0.1 \pm 0.004$ \\
\hline
\end{tabular}

Table 2. Effect of water availability in the growth medium (irrigation vs. drought) and K concentration in irrigation water (normal K vs. low K) on shoot length, leaf area and root dry weight. Shoot length and leaf area were measured only on that part of the plant growing during the experimental period. Root dry weight refer to total growth. For all treatments, values are means of 10 replications \pm standard error. Interaction between water availability and $\mathrm{K}$ concentration was significant for all parameters analyzed.

\begin{tabular}{lccr}
\hline & $\begin{array}{c}\text { Shoot } \\
\text { length } \\
(\mathrm{cm})\end{array}$ & $\begin{array}{c}\text { Leaf } \\
\text { area } \\
\left(\mathrm{cm}^{2}\right)\end{array}$ & $\begin{array}{c}\text { Root } \\
\text { dry wt } \\
(\mathrm{g})\end{array}$ \\
Treatment & $53.9 \pm 1.8$ & $155.8 \pm 5.3$ & $0.7 \pm 0.02$ \\
Irrigated-normal K & $37.5 \pm 2.0$ & $103.1 \pm 7.6$ & $0.8 \pm 0.04$ \\
Irrigated-low K & $7.4 \pm 1.4$ & $17.1 \pm 4.4$ & $0.8 \pm 0.02$ \\
Drought-normal K & $8.1 \pm 1.0$ & $16.6 \pm 2.7$ & $0.9 \pm 0.06$ \\
Drought-low K & & & 0.9 \\
\hline
\end{tabular}

Table 3. Effect of water availability in the growth medium (irrigation vs. drought) and K concentration in irrigation water (normal K vs. low K) on water content ( $\mathrm{g} \cdot \mathrm{g}^{-1}$ dry weight) in leaves, shoots, and roots.

\begin{tabular}{|c|c|c|c|}
\hline Parameter & Leaf & Shoot & Root \\
\hline \multicolumn{4}{|l|}{ Treatment } \\
\hline Irrigated-normal K & $1.8 \pm 0.02$ & $1.9 \pm 0.05$ & $6.7 \pm 0.14$ \\
\hline Irrigated-low K & $1.6 \pm 0.03$ & $1.6 \pm 0.02$ & $6.3 \pm 0.22$ \\
\hline Drought-normal K & $1.3 \pm 0.07$ & $1.4 \pm 0.15$ & $5.7 \pm 0.17$ \\
\hline Drought-low K & $1.3 \pm 0.03$ & $1.3 \pm 0.10$ & $5.3 \pm 0.21$ \\
\hline \multicolumn{4}{|l|}{ Water } \\
\hline Irrigated & $1.7 \mathrm{~A}^{\mathrm{z}}$ & $1.8 \mathrm{~A}$ & $6.5 \mathrm{~A}$ \\
\hline Drought & $1.3 \mathrm{~B}$ & $1.4 \mathrm{~B}$ & $5.5 \mathrm{~B}$ \\
\hline \multicolumn{4}{|l|}{$\mathrm{K}^{+}$} \\
\hline Normal K & $1.5 \mathrm{a}$ & $1.7 \mathrm{a}$ & $6.2 \mathrm{~A}$ \\
\hline Low K & $1.4 \mathrm{~b}$ & $1.5 \mathrm{~b}$ & $5.8 \mathrm{~B}$ \\
\hline
\end{tabular}

${ }^{\mathrm{z}}$ For all treatments, values are means of 10 replications \pm standard error. Different letters indicate significant differences between levels for the same factor, at $p<0.05$ (lower case letters) and $p<0.01$ (upper case letters).

drought plants, shoot and leaf growth was inhibited, and $\mathrm{K}$ starvation (low $\mathrm{K}$ ) had no additional effect; by contrast, in well-watered plants, K starvation significantly inhibited leaf and shoot growth. Conversely, both K starvation and drought conditions favored root growth (Table 2).

Water content in leaves, shoots, and roots increased as availability of both water and $\mathrm{K}$ in the growth medium increased (Table 3 ). Within each watering regime, the best-hydrated plants were those displaying higher K content (Tables 1 and 3); as expected, well-watered plants were better hydrated than those undergoing drought. Therefore, availability of both water and $\mathrm{K}$ in the growth medium, favored plant hydration. However, water-use efficiency, as expressed by shoot growth, varied in response to changes in these two factors (Fig. 1): well-watered plants displayed lower water-use efficiency than water-deficit plants, while plants receiving a higher concentration of $\mathrm{K}$ used water more efficiently than K-starved plants in both watering regimes (Fig. 1).

To account for the effect of $\mathrm{K}$ status on water-use efficiency, stomatal conductance was measured throughout the day. For all treatments, stomatal conductance was very low at night, but started to rise three hours before dawn; this trend was more marked in the irrigated treatments than in the drought treatments (Fig. 2). After sunrise, there was a more pronounced increase in conductance, which attained maximum values at noon in well-watered plants and roughly two hours earlier in plants undergoing water deficit. In all treatments, stomatal conductance gradually declined through the afternoon and evening, reaching minimum values at night. Throughout the day, conductance was greater in well-watered than in water-deficit plants and, within each of these watering regimes, overall stomatal conductance throughout the day was greater in K-starved plants (low K) than in well-nourished plants (normal K) (Fig. 2 ). The effect of $K$ starvation on conductance was apparent throughout the day in plants undergoing water deficit, whereas it was observed mainly in the afternoon/evening in well-watered plants.

As far as we know, it is the first time that it has been described that a moderate potassium deficiency in olives induces an important lose of water, being this phenomenon related to a bigger stomatal conductance.

The results of the present study, using 'Chemlali de Sfax' (which is well adapted to low-rainfall areas in southern Tunisia), suggest that $\mathrm{K}$ plays a major role in regulating water status in olive. Plants receiving adequate $\mathrm{K}$ nutrition displayed greater water-use efficiency, greater leaf water content and lower transpiration rates than $\mathrm{K}$-starved plants. This positive effect of $\mathrm{K}$ on plant water status in the olive is enhanced by availability of water in the growth medium.

Of all the mechanisms involved in water flow through the plant, stomatal opening and closure is the most widely studied (Assmann and Shimazaki, 1999). A number of studies have shown that, in the olive, this is the most 


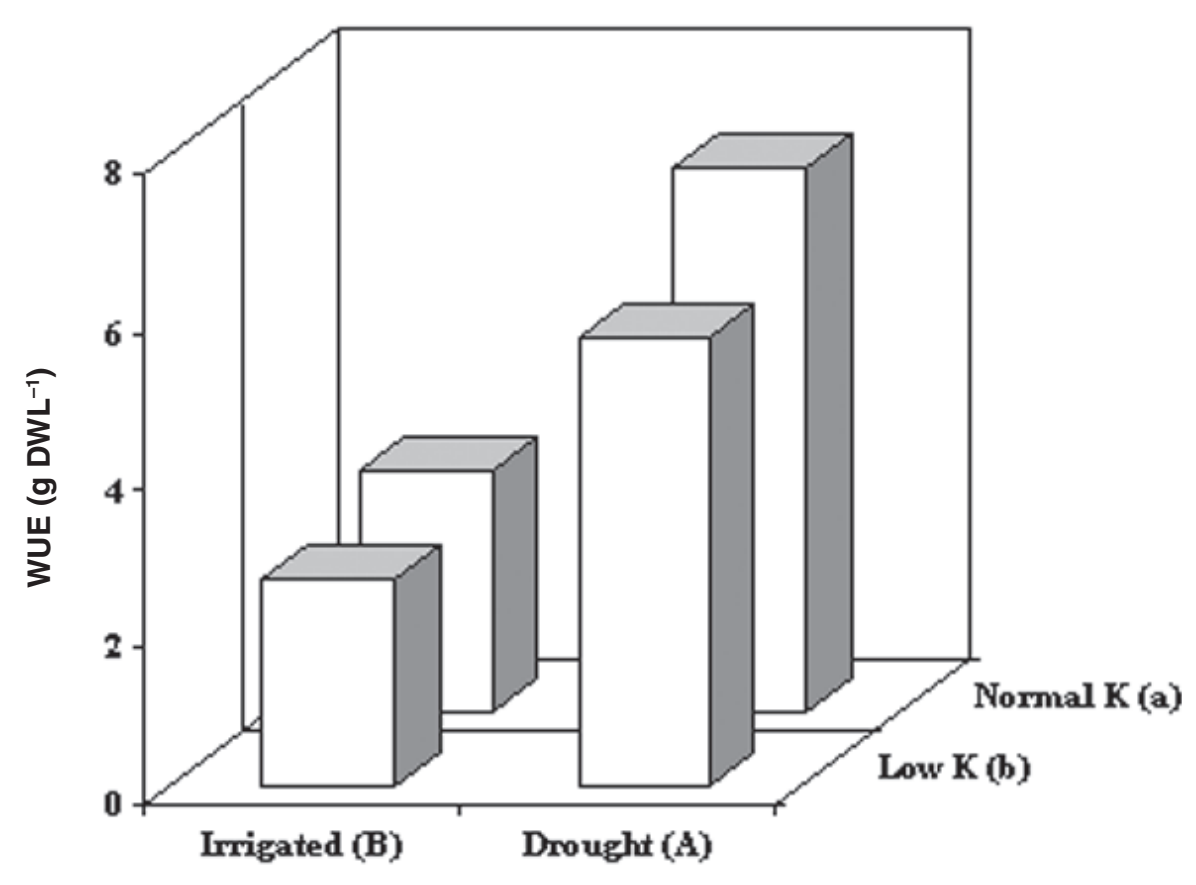

Fig. 1. Effect of water availability in the growth medium (irrigation vs. drought) and $\mathrm{K}$ concentration in irrigation water (normal $\mathrm{K}$ vs. low $\mathrm{K}$ ) on water-use efficiency (WUE). Values are the mean of 10 replicates. Different letters indicate significant differences between levels for the same factor, at $p<0.05$ (lower case letters) and $p<0.01$ (upper case letters).

effective mechanism for avoiding water loss in water stress situations (Deidda et al., 1990; Fernández et al., 1997; Giménez et al., 1997; Giorio et al., 1999; Gucci et al., 2002; Moriana et al., 2002). Although the involvement of $\mathrm{K}$ in this mechanism has been documented for many years (Fischer, 1968; Fujimo, 1967), less is known about the stomatal behavior in cases of $\mathrm{K}$ deficiency. Results in this area are somewhat contradictory: while some authors report that $\mathrm{K}$ deficiency may favor stomatal opening and thus increasing transpiration (Bednarz et al., 1998; Brag, 1972; Lindhauer, 1985; Sudama et al., 1998), others have found that $\mathrm{K}$ deficiency actually favors stomatal closure (Dhakal and Erdei, 1986; Smith and Stewart, 1990; Tomemori et al., 2002). According to

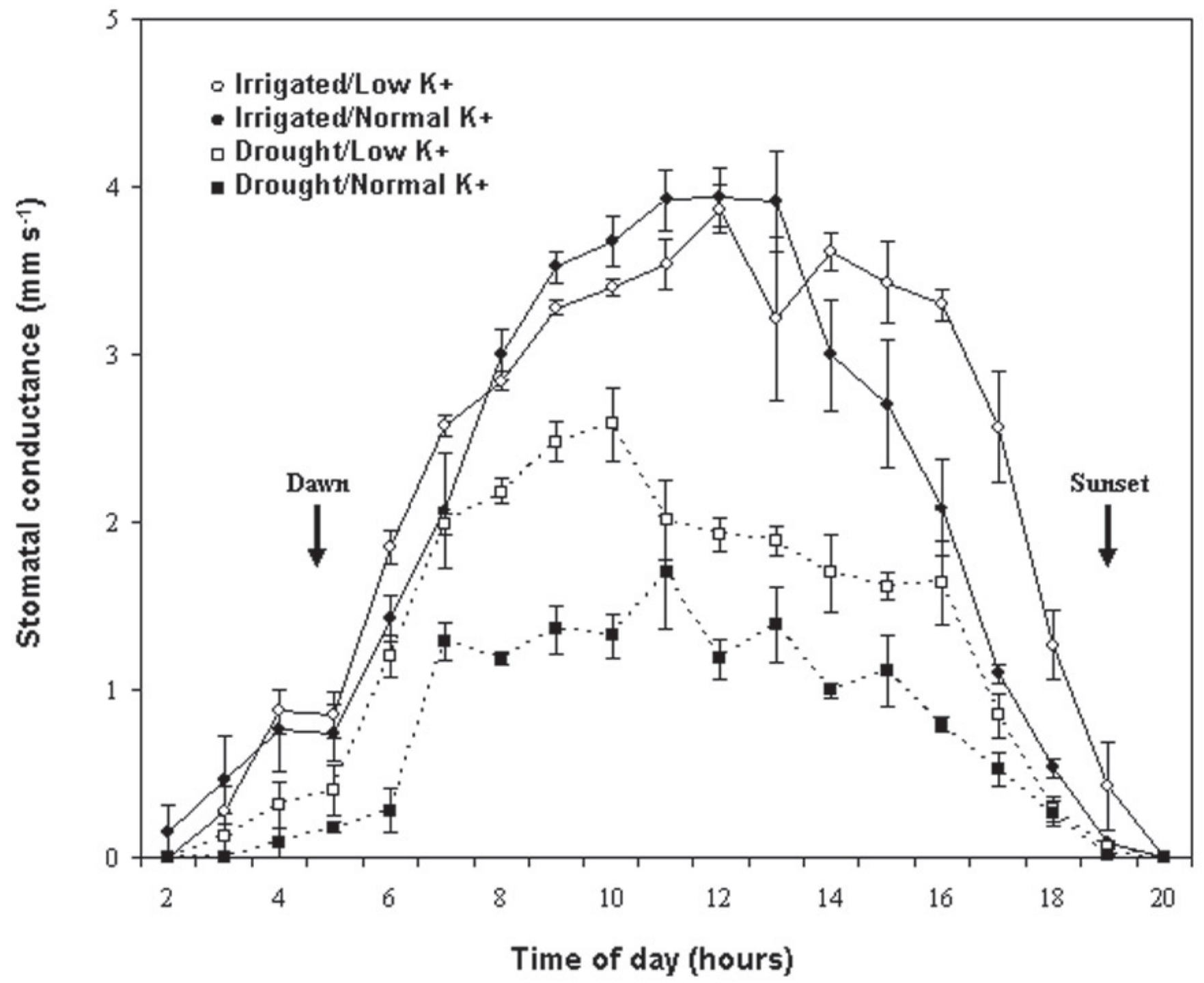

Fig. 2. Effect of water availability in the growth medium (irrigation vs. drought) and $\mathrm{K}$ concentration in irrigation water (normal $\mathrm{K}$ vs. low $\mathrm{K}$ ) on stomatal conductance throughout the day on 22 Aug. For all treatments, values are means of nine replications \pm standard error. 
other research, potassium status has no effect at all on the stomatal mechanism (Ashraf et al., 2001; Basile et al., 2003; Longstreth and Nobel, 1980; People and Koch, 1979).

A number of hypotheses have been put forward to account for these contradictory results. Hsiao and Läuchli (1986) argue that most studies attributing stomatal closure to $\mathrm{K}$ deficiency have tended to focus on plants at a very advanced stage of nutritional deficit; Bednarz et al. (1998) report that moderate $\mathrm{K}$ deficiency directly affects stomatal conductance, whereas more severe deficiency may affect other metabolic processes and, in doing so, modify the initial stomatal response to deficiency. Moreover, possible differences in response to $\mathrm{K}$ deficiency between species cannot be ruled out.

A direct relationship has been reported between stomatal conductance and water status in the olive (Moriana et al., 2002). This effect was not observed here for K nutrition: $\mathrm{K}$-starved plants displayed both lower water content and greater stomatal conductance, as well as greater daily stomatal opening rates, than plants with an adequateK supply. This effect was influenced by the availability of water in the growth medium; in drought conditions, stomatal conductance was greater throughout the day in K-starved plants, whereas in wellwatered plants this effect was apparent only in the evening. These results suggest that $\mathrm{K}$ starvation in olive trees may impair the plant's ability to regulate stomatal closure; this may account for the dehydration observed in Kstarved plants, particularly in situations of water stress.

A recent study reports that, in sunflower, ABAonly inhibits water flux in plants receiving an adequate $\mathrm{K}$ supply, whereas it has no effect in K-starved plants (Fournier et al., 2005). The same may be true in the olive, giving rise to the dehydration of $\mathrm{K}^{+}$-starved plants, particularly in water stress conditions.

\section{Literature Cited}

Abdel-Wahab, A.M. and M.H. Abd-Alla. 1995. The role of potassium fertilizer in nodulation and nitrogen fixation of faba beans (Vicia faba L.) plants under drought stress. Biol. Fert. Soils 20:147-150.

Ashraf, M.,A.Ashraf, and T.McNeilly. 2001. Growth and photosynthetic characteristics in pearl millet under water stress and different potassium supply. Photosynthetica 39:389-394.

Assmann, S.M. and K. Shimazaki.1999. The multisensory guard cell. Stomatal responses to blue light and abcisic acid. Plant Physiol. 119:809-815.

Bacelar, E.A., C.M. Correia, J.M. Moutinho-Pereira, B.C. Gonçalves, J.I. Lopez, and J.M.G. TorresPereira. 2004. Sclerophylly and leaf anatomical traits of five field-grown olive cultivars growing under drought conditions. Tree Physiol. 24:233-239.
Basile, B., E.J. Reidel, S.A. Weinbaum, and T.M. DeJong. 2003. Leaf potassium concentration, $\mathrm{CO}_{2}$ exchange and light interception in almond trees (Prunus dulcis (Mill) DA Webb). Sci. Hort.-Amsterdam 98:185-194.

Bednarz, C.W., D.M. Oosterhuis, and R.D. Evans. 1998. Leaf photosynthesis and carbon isotope discrimination of cotton in response to potassium deficiency. Environ. Expt. Bot. 39:131-139.

Brag, H. 1972. The influence of potassium on the transpiration rate and stomatal opening in Triticum aestivum and Pisum sativum. Physiol. Plantarum 26:250-257.

De la Guardia, M.D. and M. Benlloch. 1980. Effects of potassium and gibberellic acid on stem growth of whole sunflower plants. Physiol. Plantarum 49:443-448.

Deidda, P, S. Dettori, M.R. Filigheddu, and A. Canu. 1990. Water stress and physiological parameters in young table-olive trees. Acta Hort. 286:255-258.

Dhakal, M-R. and L. Erdei. 1986. Long-term effects of abscisic acid on $\mathrm{K}^{+}$transport in young wheat plants of different $\mathrm{K}^{+}$status. Physiol. Plantarum 68:637-640.

Fereres, E. 1984. Variability in adaptative mechanisms to water deficits in annual and perennial crop plants. B. Soc. Bot. Fr.- Actual 131:17-32.

Fernández, J.E., F. Moreno, I.F. Giron, and O.M. Blázquez. 1997. Stomatal control of water use in olive tree leaves. Plant Soil 190:79-192.

Fernández-Escobar, R., T. García-Barragán, and M. Benlloch. 1994. Estado nutritivo de las plantaciones de olivar en la provincia de Granada. ITEA 90:39-49.

Fischer, R.A. 1968. Stomatal opening: role of potassium uptake by guard cells. Science 160:784-785.

Fournier, J.M., A.M. Roldán, C. Sánchez, G. Alexandre, and M. Benlloch. 2005. $\mathrm{K}^{+}$starvation increases water uptake in whole sunflower plants. Plant Sci. 163:823-829.

Fujimo, M. 1967. Role of adenosinetriphosphate and adenosinetriphosphatase in stomatal movement. Sci. B. Fac. Nagasaki Uni. 18:1-47.

Giménez, C., E. Fereres, C. Ruz, F. Orgaz, and K.S. Chartzoulakis, 1997. Water relations and gas exchange of olive trees: Diurnal and seasonal patterns of leaf water potential, photosynthesis and stomatal conductance. Acta Hort. 449:411-415.

Giorio, P., G. Sorrentino, and R. D’Andria. 1999. Stomatal behaviour, leaf water status and photosynthetic response in field-grown olive under water deficit. Environ. Expt. Bot. 42:95-104.

Gucci, R., R. Massai, S. Casano, G. Costagli, I.T. Metzidakis, and D.G. Voyiatzis. 1999. The effect of leaf age on $\mathrm{CO} 2$ assimilation and stomatal conductance of field-grown olive trees. Acta Hort. 474:289-292.

Gucci, R., A. Grimelli, G. Costagli, R. Tognetti, A. Minnocci, and C. Vitagliano. 2002. Stomatal characteristics of two olive cultivars 'Frantoio' and 'Leccino'. Acta Hort. 586:541-544.

Hsiao, T.C. and A. Läuchli. 1986. Role of potassium in plant-water relations, p. 281-312. In: B. Tinker andA. Läuchli (eds.).Advances in plant nutrition. vol. 2. Praeger Scientific, New York.

Läuchli, A. 1984. Mechanisms of nutrient fluxes at membranes of the root surface and their regulation in the whole plant, p. 1-25. In: S.A. Barber and D.R. Bouldin(eds.). Roots, nutrient and water influx, and plant growth. SSSA-CSSA-ASA Spec. Publ. 49.

Lindhauer, M.G. 1985. Influence of K nutrition and drought on water relations and growth of sunflower (Helianthus annuus L.). Z. Pflanz. Bodenkunde. 148:654-669.

Longstreth, D.J. and P.S. Nobel. 1980. Nutrient influences on leaf photosynthesis. Effects of nitrogen, phosphorus and potassium for Gossypium hirsutum L. Plant Physiol. 65:541-543.

Mengel, K. and W.W. Arneke. 1982. Effect of potassium on the water potential the osmotic potential, and cell elongation in leaves of Phaseolus vulgaris. Physiol. Plant 54:402-408.

Mengel, K. and E. Kirkby. 1987. Principles of plant nutrition. International Potash Inst., Worblaufen-Bern.

Moriana, A., F.J. Villalobos, and E. Fereres. 2002. Stomatal and photosynthetic responses of olive (Olea europaea L.) leaves to water deficits. Plant Cell Environ. 25:395-405.

Orgaz, F. and E. Fereres. 2001. Riego, p. 287-308. In: D. Barranco, R. Fernández-Escobar, and L. Rallo (eds.). El cultivo del olivo. 4th ed. MundiPrensa and Junta de Andalucía, Madrid.

Parra, M.A., R. Fernández-Escobar, C. Navarro, and O. Arquero. 2003. Los suelos y la fertilización del olivar cultivado en zonas calcáreas. Junta de Andalucía and Mundi-Prensa, Madrid.

People, T.R. and D.W. Koch. 1979. Role of potassium in carbon dioxide assimilation in Medicago sativa L. Plant Physiol. 63:878-881.

Quintero, J.M., J.M. Fournier, J. Ramos, and M. Benlloch. 1998. K+ status and ABA affect both exudation rate and hydraulic conductivity in sunflower roots. Physiol. Plantarum 102:279-284.

Rapoport, H. 2001. Botánica y morfología, p. 35-60. In: D. Barranco, R. Fernández-Escobar, and L. Rallo(eds.). El Cultivo del Olivo. 4th ed. MundiPrensa and Junta de Andalucía, Madrid.

Smith, S. and G.R. Stewart. 1990. Effect of potassium levels on the stomatal behavior of the hemiparasite Striga hermonthica Plant Physiol. 94:1472-1476.

Sudama, S., T.N. Tiwari, R.P. Srivastava, G.P. Singh, and S. Singh. 1998. Effect of potassium on stomatal behaviour, yield and juice quality of sugarcane under moisture stress condition. Ind. J. Plant Physiol. 3:303-305.

Tiwari, H.S., R.M. Agarwal, and R.K. Bhatt. 1998. Photosynthesis, stomatal resistance and related characteristics as influenced by-potassium under normal water supply and water stress conditions in rice (Oryza sativa L.). Indian J. Plant Physiol. 3:314-316.

Tomemori, H., K. Hamamura, and K. Tanabe. 2002. Interactive effects of sodium and potassium on the growth and photosynthesis of spinach and komatsuna. Plant Prod. Sci. 5:281-285.

Wyn Jones, R.G., C.J. Brady, and J. Speirs. 1979. Ionic and osmotic relations in plant cells, $\mathrm{p}$. 63-103. In: D.L. Laidman and R.G. Wyn Jones (eds.). Recent advances in the biochemistry of cereals. Academic Press, London.

Xiloyannis, C., B. Dichio, V. Nuzzo and G. Celano. 1999. Defence strategies of olive against water stress. Acta Hort. 474:423-426. 